\title{
Osteoclastoma of Proximal Ulna-Atypical Location in a 13-Year-Old Child
}

\author{
Siddaram Patil, Ranjit Kumar Yalamanchili \\ Mamata Medical College, Khammam, India \\ Email: drsnp_2006@yahoo.co.in
}

Received 5 January 2014; revised 10 February 2014; accepted 18 February 2014

Copyright (C) 2014 by authors and Scientific Research Publishing Inc.

This work is licensed under the Creative Commons Attribution International License (CC BY). http://creativecommons.org/licenses/by/4.0/ (c) (i) Open Access

\begin{abstract}
Giant cell tumour (GCT) or osteoclastoma is a very rare locally invasive bone tumour that occurs close to the joint. The ulnar metaphysis is an unusual site for an Osteoclastoma with occurrence rate of $0.45 \%$ to $3.2 \%$ as reported in literature [1]. Most of the patients seek traditional methods of treatment before orthopaedic consultation and present lately with extensive involvement of the tumour into soft tissues and articular surface, making the joint preservation difficult or impossible. For reconstruction, several options have been described, which include fibular autografts, allografts and cement augmentation. Inherent to all these procedures is the risk of delayed union of the graft and preserving functional mobility of the joint. We report a rare case of a proximal ulna GCT diagnosed in a 13-year-old girl. It was treated with intralesional curettage, and autologous maternal iliac crest bone grafting augmented with bone cement reconstruction.
\end{abstract}

\section{Keywords}

Ulna; Bone Cement; Bone Graft

\section{Introduction}

Giant cell tumour (GCT) or osteoclastoma is a very rare locally invasive bone tumour that occurs close to the joint. It is generally benign but locally aggressive variant [2]. It represents approximately $3 \%$ to $5 \%$ of all primary bone cancers [2]. It usually occurs in adults in $2^{\text {nd }}$ to $4^{\text {th }}$ decades of life. However, GCT of bone is uncommon in children younger than 15 years and in adults older than 65 years of age [1]. The ulnar metaphysis is an unusual site for an Osteoclastoma with occurrence rate of $0.45 \%$ to $3.2 \%$ as reported in literature [1]. Typically the tumour appears to be an expanded radiolucent lesion located in the epiphyseal end of the tubular bone. The tumour extends mainly proximally and distally involving articular surface and metaphysis of the bone. As the bone expands, the surrounding cortex is thinned. The radiolucencey of a giant cell tumour is due to massive de- 
struction of the cortical and cancellous bone without any calcification or periosteal reaction. Although giant cell tumours of bone are common in distal radius, proximal humerus and distal humerus, its occurrence in proximal ulna is extremely rare as reported in this case. Due to its aggressive nature and high chances of recurrence, enbloc resection is the standard recommended option [3]. Most of the patients seek traditional methods of treatment before orthopaedic consultation and present lately with extensive involvement of the tumour into soft tissues and articular surface, making the joint preservation difficult or impossible. For reconstruction, several options have been described, which include fibular autografts, allografts and cement augmentation. Inherent to all these procedures is the risk of delayed union of the graft and preserving functional mobility of the joint. We report a rare case of a proximal ulna GCT diagnosed in a 13-year-old girl. It was treated with intralesional curettage, and autologous maternal iliac crest bone grafting augmented with bone cement reconstruction.

\section{Case Report}

A 13-year-old female child presented with history of pain and swelling over her left elbow since 20 days. Child noticed swelling after she had pain over elbow due to a blunt injury. Diffuse swelling without any engorged veins, scars, abscess or sinus was seen over postero-medial aspect of proximal ulna starting from inferior aspect of elbow. There was local tenderness over olecranon and proximal ulna without local raise of temperature. Three point bony relation of humeral epicondyles and olecranon was maintained and there was no abnormality in the carrying angle of elbow on affected side. She had restriction of movements at the elbow joint.

Radiographs of elbow showed lytic lesions in proximal ulna with periosteal reaction suggestive of GCT, Aneurysmal Bone cyst, unicameral bone cyst (Figure 1). ESR was raised (40 mm) and total blood count, differential count, CRP was normal (to rule out infectious focus).

MRI depicts a hypointensity in the T1 sequences with hyperintensity in the STIR sequences and enhancement after Gadolinium contrast administration (Figure 2) probably due to the presence of newly formed tissue. MRI concludes it as a benign variant without soft tissue extension of the tumour. Hence, we planned for curettage and further histopathological analysis.

A cortical bony window was made in the raw area of lesion through a postero-medial approach to the selling over proximal ulna. Accessing the lesion, the cystic cavity revealed a gelatinous "chocolate brown" material with many areas of darker colour. After thorough curettage, the cavity measured about 36 cc was packed with cortico-cancellous allograft taken from maternal iliac crest after due cross-matching and was augmented with bone cement (Figure 3). We believed that exothermic property of bone cement would act as a local adjuvant to prevent recurrence apart from adding strength to the large curetted lesion.

Histopathologically the tumour was graded as Type-II according to the Campanacci Classification system and as stage II benign tumour without extramedullary extent according to the Enneking Classification for benign bone tumours (Figure 4).

We followed the case up to 3 months until patient improved elbow movements to functional extent (10 - 130 degrees) and radiological consolidation of graft at the edges of lesion was evident (Figure 5). However, follow-
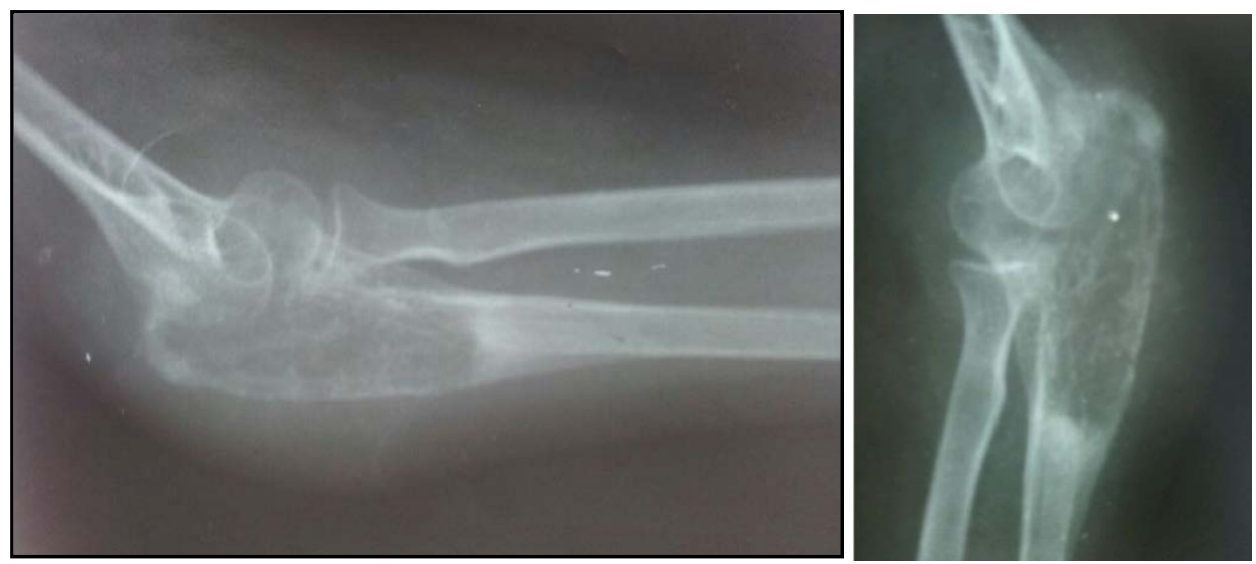

Figure 1. Pre-operative radiograph showing a osteolytic expansile lesion in the metaphysic extending up to subchondral bone and periosteal reaction. 

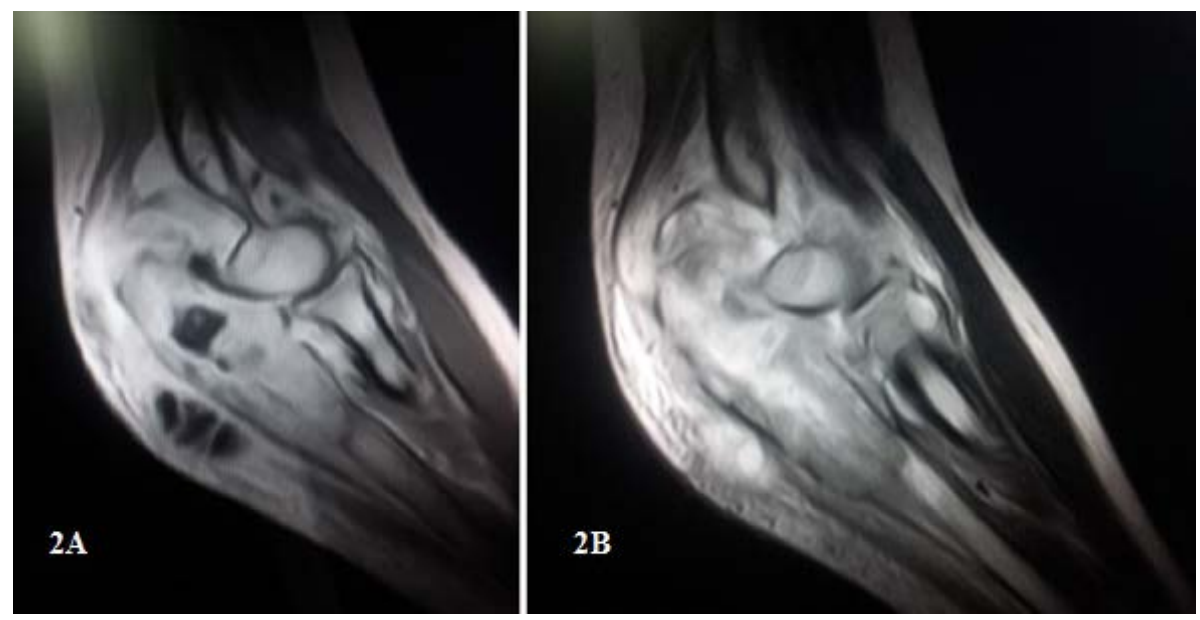

Figure 2. (A) Coronal T2 weighted GRE sequence showing lesion in proximal ulna; (B) Coronal T2 weighted GRE sequence showing enhancement on contrast administration.
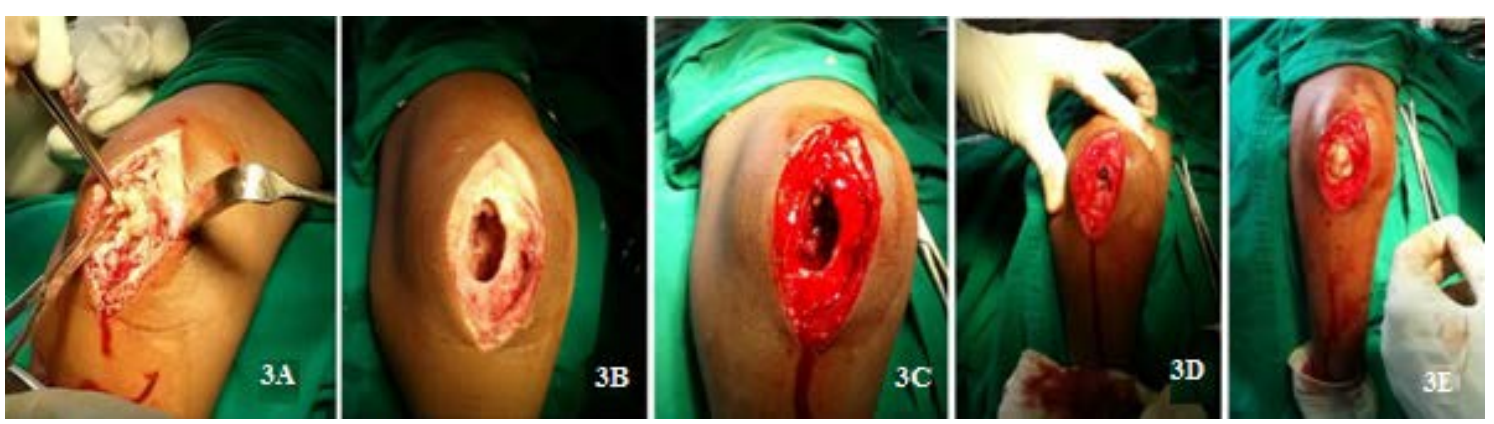

Figure 3. Intra-operative pictures. (A) tumour mass removal; (B) tumour cavity touriniquet; (C) Bleeding after removal of tourniquet; (D) Bone graft from maternal iliac crest; (E) Remaining cavity filled with bone cement.

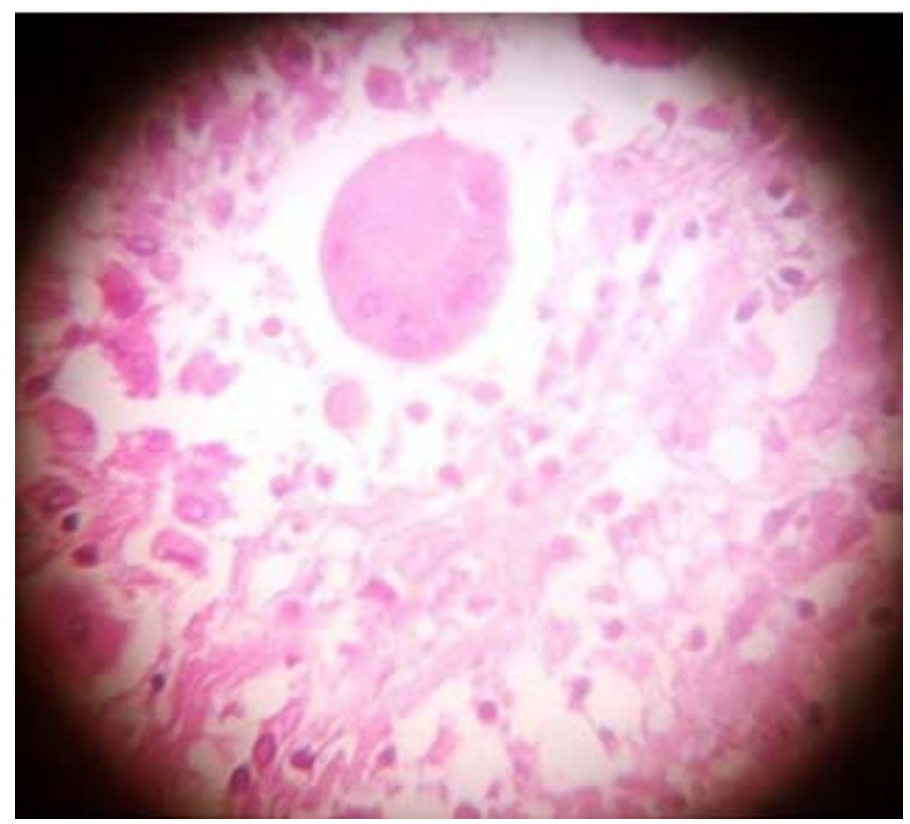

Figure 4. Histopathological slide showing osteoclastic giant cells, inflammatory cells, plasma cells amidst stroma containing spindle cells with few myxoid areas. 


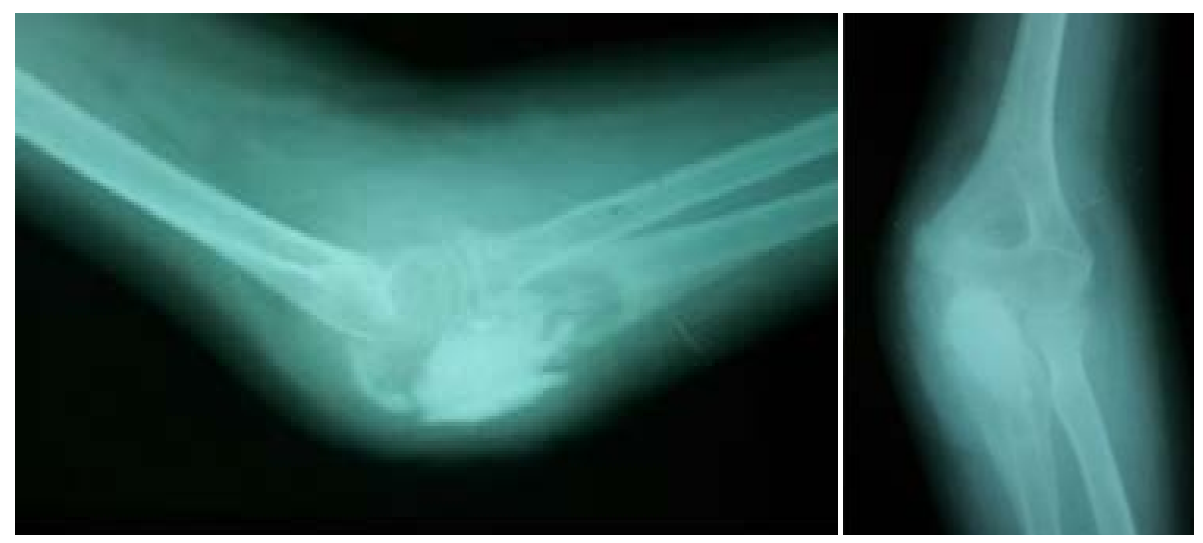

Figure 5. Post-operative Radiographs after intralesional curettage and autologous corticocancellous maternal bone grafting with PMMA adjuvant augmentation.

up to evaluate recurrence and malignant transformation is awaited. The interval between surgery and local recurrence reported, is an average of19 months duration as reported in literature [4].

\section{Discussion}

Osteoclastoma is a rare benign tumour which can turn out as aggressive regardless of its radiological or histological characteristics. It is typically located in the meta-epiphyseal region of long bones involving the subchondral region but sparing the articulation. Extension of the tumour into the metaphysis and very rarely in to the diaphysis is seen in cases of larger lesions [5]-[7].

GCT must be distinguished from other giant cell variants (which histologically show the osteoclastic giant cells) that include aneurysmal bone cyst, osteoclastoma, chondroblastoma, unicameral bone cyst, chondromyxoid fibroma, non osteogenic fibroma, fibrous dysplasia, brown tumor of hyperparathyroidism [8].

The goal of management should be complete ablation to prevent recurrence and preserving the joint articulation [9]. Preserving the joint congruity may not always be possible, particularly in cases of recurrences or aggressive lesions [10] [11]. Campanacci grade III giant cell lesions are characterized by fuzzy borders with loss of cortical continuity and extension into soft tissues that reflects their aggressive nature. In such cases, limb salvage with wide excision instead of intralesional curettage may be advocated. Although an en-bloc resection radically removes the tumour and risk of recurrence, functional outcome is poor [11]. In Grade II lesions that behave less aggressively, intralesional curettage with allograft and adjuvant therapy with bone cement (PMMA) is beneficial in retaining anatomical articulation [10]. An intralesional curettage although provides an excellent functional outcome, it is associated with $40 \%$ chances of recurrence [9] Intralesional curettage coupled with adjuvant ablation of the tumour cavity using phenol, polymethyl methacrylate (PMMA) or cryotherapy have decreased with chances of recurrence to $18 \%$ [12]-[14]. The rate of recurrence ranges from $5 \%$ to $8 \%$ when bone cement is used, and approximately $2.3 \%$ after cryosurgery [12] [13]. According to Schajowicz [15] curettage alone is an inadequate oncological procedure, but when an adjuvant like bone cement is used, it provides a good result with respect to decreased chances of reccurence and better functional outcome.

The treatment options should always consider oncological radicality of the tumour and the restoration of functionality [15]-[17]. In the present case scenario intralesional curettage was possible as the tumour was a grade II lesion and the reconstruction was carried out with augmentation of bone cement with autologous cortico-cancellous bone graft from maternal iliac crest as the child is young.

\section{Conclusion}

Diagnosing osteolytic lesions at long bone epiphysis is difficult and requires a great deal of experience and often can be misinterpreted, especially in young patients. It is always important to know atypical locations of a bone tumour, so that the diagnosis cannot be missed. When considering clinical, radiological and histological findings, the diagnosis of a GCT can be readily made even in atypical locations and when treated early and radically, recurrence can be avoided with good prognosis. 


\section{References}

[1] Daniele, V., Andrea, P., Elda, A., Patrizio, C. and Vincenzo, S.(2012) Giant Cell Tumor of the Distal Ulna: A Case Report. Journal of Medical Case Reports, 6, 143. http://dx.doi.org/10.1186/1752-1947-6-143

[2] Ng, E.S., Saw, A., Sengupta, S. and Nazarina, A.R. (2002) Giant Cell Tumour of Bone with Late Presentation: Review of Treatment and Outcome. Journal of Orthopaedic Surgery, 10, 120-128.

[3] Harness, N.G. and Mankin, H.J. (2004) Giant Cell Tumor of the Distal Forearm. Journal of Hand Surgery, 29A, 188-193. http://dx.doi.org/10.1016/j.jhsa.2003.11.003

[4] Campanacci, M., Baldini, N., Boriani, S. and Sudanese, A. (1987) Giant-Cell Tumour of Bone. The Journal of Bone \& Joint Surgery, 69, 106-114.

[5] Beebe-Dimmer, J.L., Cetin, K., Fryzek, J.P., Schuetze, S.M. and Schwartz, K. (1975) The Epidemiology of Malignant Giant Cell Tumors of Bone: An Analysis of Data from the Surveillance, Epidemiology and End Results Program (1975-2004).

[6] Campanacci, M., Baldini, N., Boriani, S. and Sudanese, A. (1987) Giant-Cell Tumor of Bone. The Journal of Bone \& Joint Surgery, 69, 106-114.

[7] Goldenberg, R.R., Campbell, C.J. and Bonfiglio, M. (1970) Giant-Cell Tumor of Bone. An Analysis of Two Hundred and Eighteen Cases. The Journal of Bone \& Joint Surgery, 52, 619-664.

[8] Peh, S.C., Cheah, P.L. and Sengupta, S. (1988) The Pathology of Tumour and “Tumour-Like” Lesions of Bone in the University Hospital Kuala Lumpur. Malays Journal of Pathology, 10, 45-50.

[9] Masui, F., Ushigome, S. and Fujii, K. (1998) Giant Cell Tumor of Bone: A Clinicopathologic Study of Prognostic Factors. Pathology International, 48, 723-729. http://dx.doi.org/10.1111/j.1440-1827.1998.tb03973.x

[10] Goldenberg, R.R., Campbell, C.J. and Bonfiglio, M. (1970) Giant-Cell Tumor of Bone. An Analysis of Two Hundred and Eighteen Cases. The Journal of Bone \& Joint Surgery, 52, 619-664.

[11] Sung, H.W., Kuo, D.P., Shu, W.P., Chai, Y.B., Liu, C.C. and Li, S.M. (1982) Giant-Cell Tumor of Bone: Analysis of Two Hundred and Eight Cases in Chinese Patients. The Journal of Bone \& Joint Surgery, 64, 755-761.

[12] Malawer, M.M., Bickels, J., Meller, I., Buch, R.G., Henshaw, R.M. and Kollender, Y. (1999) Cryosurgery in the Treatment of Giant Cell Tumor. A Long-Term Follow-Up Study. Clinical Orthopaedics and Related Research, 359, 176-188. http://dx.doi.org/10.1097/00003086-199902000-00019

[13] Malawer, M.M., Marks, M.R., McChesney, D., Piasio, M., Gunther, S.F. and Schmookler, B.M. (1988) The Effect of Cryosurgery and Polymethyl Methacrylate in Dogs with Experimental Bone Defects Comparable to Tumor Defects; Clinical Orthopaedics and Related Research, 226, 299-310.

[14] Marcove, R.C., Weis, L.D., Vaghaiwalla, M.R., Pearson, R. and Huvos, A.G. (1978) Cryosurgery in the Treatment of Giant Cell Tumors of Bone. A Report of 52 Consecutive Cases. Cancer, 41, 957-969. http://dx.doi.org/10.1002/1097-0142(197803)41:3<957::AID-CNCR2820410325>3.0.CO;2-Y

[15] Gracia, I., Proubasta, I.R., Trullols, L., Peiró, A., Moya, E., Cortés, S., Buezo, O. and Majó, J. (2011) Distal Radioulnar Joint Prosthesis for the Treatment of Giant Cell Tumor of the Distal Ulna: A Case Report and Literature Review. Strategies Trauma Limb Reconstruction, 6, 103-106. http://dx.doi.org/10.1007/s11751-011-0113-4

[16] Singh, M., Sharma, S., Peshin, C., Wani, I.H., Tikoo, A., Gupta, S.K. and Singh, D. (2009) Wide Resection and Stabilization of Ulnar Stump by Extensor Carpi Ulnaris for Giant Cell Tumor of Distal Ulna: Two Case Reports. Cases Journal, 2, 8617. http://dx.doi.org/10.4076/1757-1626-2-8617

[17] Burke, C.S., Gupta, A. and Buecker, P. (2009) Distal Ulna Giant Cell Tumor Resection with Reconstruction Using Distal Ulna Prosthesis and Brachioradialis Wrap Soft Tissue Stabilization. Hand (New York), 4, 410-414. http://dx.doi.org/10.1007/s11552-009-9192-9 